\title{
Effect of Intraperitoneal Application of 1\% Methylene Blue Solution on Prevention and/or Reduction of Adhesion Following Laparotomy in Rabbits
}

Bahjat Taifor Abbas ${ }^{1}$ and Sozan Ali Mohammed

Department of Surgery and Theriogenology, College of Veterinary Medicine,

University of Sulaimani, Kurdistan region- Iraq 1-drbahjatabbas@yahoo.com; Mobile: +9647701614080

\begin{abstract}
Summary
The effect of $1 \%$ methylene blue solution was investigated in this experimental trial for prevention and/or reduction of intra-abdominal adhesion formation, following induction of conventional laparotomy, by postmortem and histopathological confirmations, in a rabbit model. Twenty adult, male, local breed rabbits were used in the study. They were allocated randomly and equally into 2 groups; Control group (CG) and Treatment group (TG). All were subjected to mid-ventral conventional laparotomy under the effect of general anesthesia, and the ascending colon was exteriorized and its serosal and subserosal layers were mechanically abraded by a dry sterile soft toothbrush. In TG, $2 \mathrm{ml}$ of sterile $1 \%$ methylene blue was applied intrapretonially prior to the routine closure of the abdominal cavities. While in CG, $2 \mathrm{ml}$ of physiological saline solution was applied intraperitonially. Post-operatively, the rabbits were monitored clinically for; gain in body weight, food intake and postoperative complications. Also, 5 rabbits from each group at the $14^{\text {th }}$ and $21^{\text {st }}$ post-operative days were scarified for intra-peritoneal adhesion formation and scoring, and biopsy collection for histopathological changes. The results revealed a significant reduction and/or prevention in the development of intra-abdominal adhesions in TG compared to CG rabbits. Whereby, the lowered adhesions grade scores rate at both P.M. schedules, and histopathologically by the normally appearing serosal and muscular layers of the caecum, compared to the abnormally higher losses in the integrity of the serosal surface, blood vessel congestion, fibrosis, and heavy infiltrated of mononuclear inflammatory cells in CG rabbits. This study concluded that, the application of $1 \%$ methylene blue solution intraperitoneally following laparotomy is useful in prevention and/or reduction of post-operative adhesions formation.
\end{abstract}

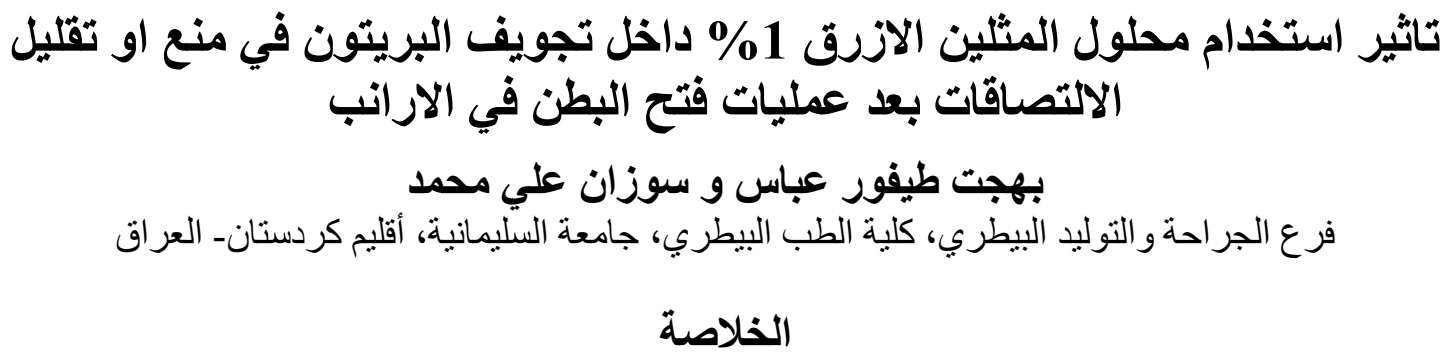

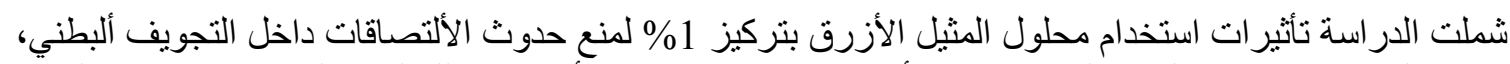

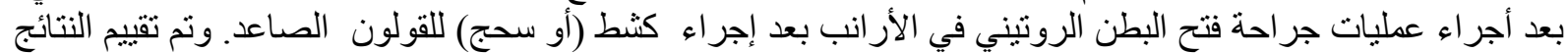

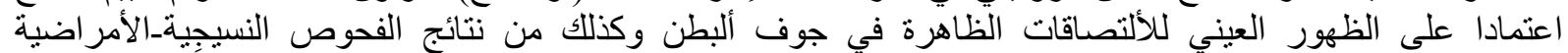

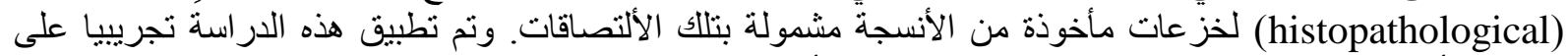

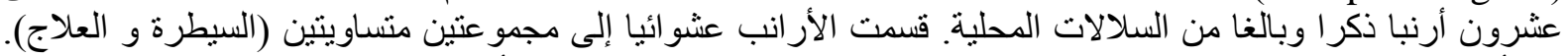

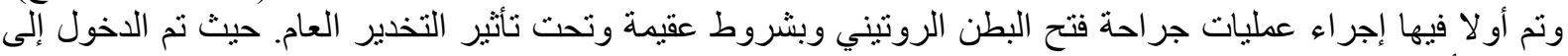

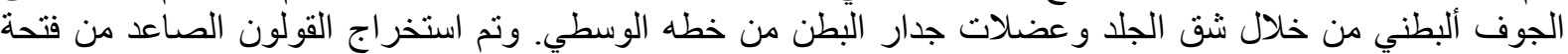

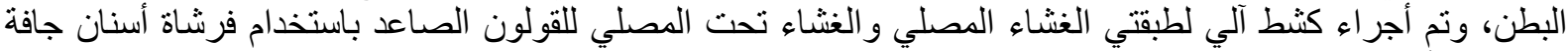

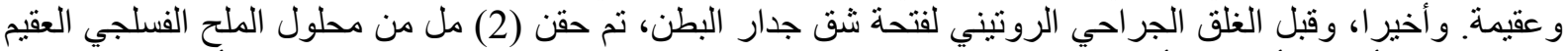

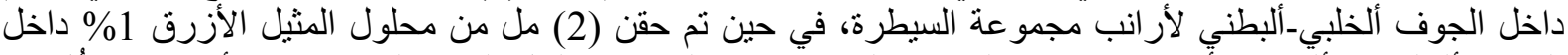

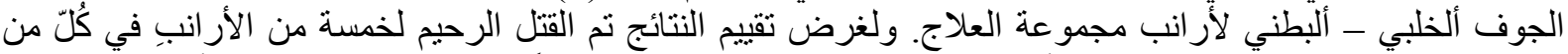

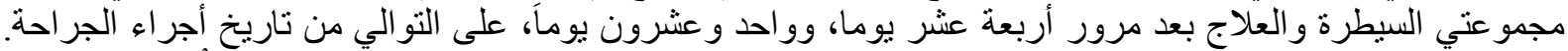

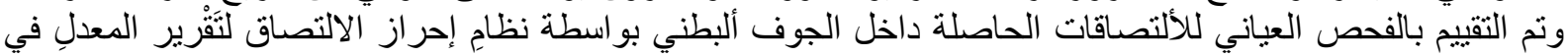




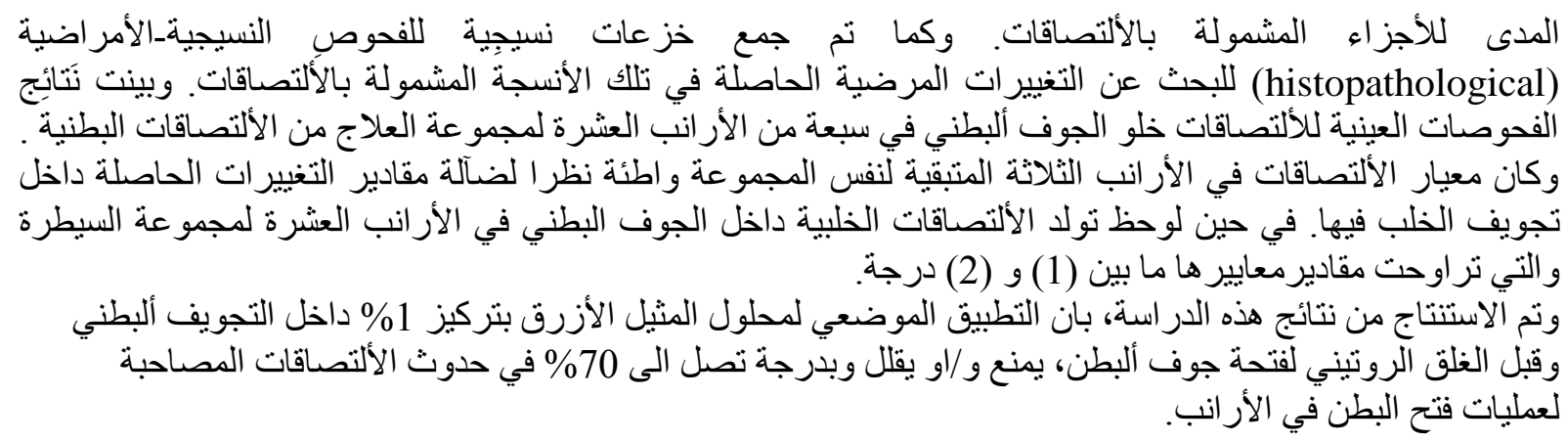

\section{Introduction}

Adhesion is an abnormal attachment that forms between tissues or organs after surgery or as a result of local inflammation. Post surgical adhesion occurs when fibrous strands of scar tissue forms, leading to abnormal joining of anatomical structures (1). They often cause internal organs and/or tissues to stick together after surgery, usually due to tissue damage caused by surgical trauma, infection, ischemia, and exposure to foreign materials (2). Incidence of postsurgical adhesion formation been estimated as high as $80 \%$ (3), and its formation after general surgical abdominal operation can occur with an incidence ranging from $67 \%$ to $93 \%$ and up to $97 \%$ after open gynecologic pelvic procedures (4). Adhesions can twist and pull organs out of their normal place and are primary causes for bowel obstruction, infertility, and chronic pelvic pain (5). The mesothelial cells of the serosal surface of the peritoneum, which covers the abdominal organs, provide a natural protective barrier that prevents the organs from adhering to adjacent apposing surfaces (6). This role is impaired when inflammatory or traumatic processes affect integrity of the serosa (7). During visceral surgery, damage to the mesothelial lining is inevitable due to desiccation, thermal injury and surgical trauma. These lesions lead to oozing out of fibrinous exudates, reduction of fibrinolytic activity and subsequent adhesion formation. The refinement of surgical technique, minimizing the peritoneal injury and avoidance of tissue ischemia markedly reduces post surgical adhesions, but do not dissolve them completely (8). The major strategies used for prevention of adhesion formation were identified by using good surgical techniques (9), and postoperative application of agents such as; NSAIDs (10), proteolytic enzymes (11), and barriers derived from organic or bioabsorbable inorganic materials $(2,12)$. Reports on Methylene Blue, a NO synthase inhibitor, has been claimed to decrease postoperative adhesion formation in a dose dependant manner in animals. In lower doses, it is preventive, whereas in higher doses it increases the extent of adhesions (13). The high affectivity of methylene blue in prevention of postoperative peritoneal adhesion formation may be through inhibition of oxygen free radicals generation and not of nitric oxide action (14).

The aim of this study was to investigate by macro- and microscopic examination the effectiveness of $1 \%$ Methylene blue applied intra-peritoneally, following conventional celiotomy and mechanical abrasions of serosal and sub-serosal layers of ascending colon, on formation of intraperitoneal adhesions in rabbit model.

\section{Materials and Methods}

Twenty young adult male local breed rabbits, physically healthy and free from congenital or acquired abnormalities with no previous surgical procedures, were used in this study. The rabbits were divided randomly and equally into 2 groups; Control Group (CG), and Treatment Groups (TG).Sterile solution of $1 \%$ Methylene blue was prepared by dissolving 1g of pure Methylene blue powder in $100 \mathrm{ml}$ of distal water and applied intraperitoneally in the TG rabbits. While, sterile physiologic saline solution $(0.09 \mathrm{NaCl}$ solutions $)$ was used for intraperitoneal application in the CG rabbits. Laparotomy was performed in all rabbits under the effect of general anesthesia. Atropine sulphate $(1 \mathrm{mg} / \mathrm{kg}$, subcutaneously) was first given (15), and followed fifteen minutes later by injection of a mixture of ketamine-xylazine $(50 \mathrm{mg} / \mathrm{kg}$ - 
$1.6 \mathrm{mg} / \mathrm{kg}$, intramuscular. When the rabbits went into surgical anesthesia, they were placed on dorsal recumbence and their ventral abdominal aspects were prepared for aspect laparotomy via a mid-ventral abdominal incision sufficient to exteriorize their ascending colon. An area extended approximately to $2-3 \mathrm{~cm}^{2}$ at the antimesentric region was abraded by mean of a dry sterile soft toothbrush, until a clearly visible erosion to the serosal and subserosal layers was observed by sight on the exteriorized ascending colon (Figure 1). The gut was returned back into the abdominal cavity. Intraperitoneal (I.P.) injection of sterile physiologic saline solution ( $2 \mathrm{ml}$ ) was applied by sterile disposable syringe into the abdominal cavities of the CG. While, sterile $1 \%$ Methylene blue solution was applied by the same technique into the abdominal cavities of TG rabbits. Finally, the abdominal walls were sutured. Postoperative care applied on the rabbits by closely monitoring their general health condition and taking care to the laparotomy wounds. Also, a daily monitor to their body weights and food intake was measured and recorded.

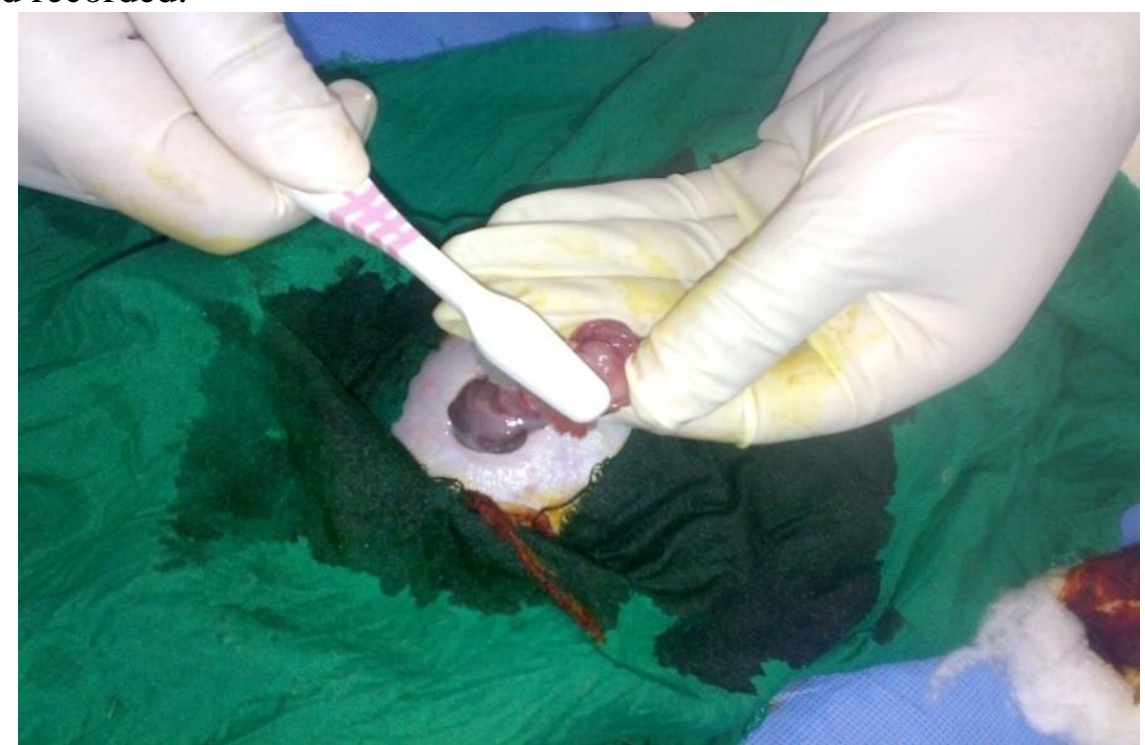

Figure 1: Mechanical abrasion of the Serosal and Subserosal layers of the ascending colon was made by a dried and soft sterile toothbrush until visible damage occurred on the abraded wall in the form of roughness and congestion.

Post-mortem (P.M.) examination and biopsy sampling for evaluation of intraperitoneal adhesions and biopsy collections: Euthanasia, at the $14^{\text {th }}$ and $21^{\text {st }}$ P.O. days, for 5 rabbits from each group with halothane over dosage was performed, to investigate the P.O. intraperitoneal changes and for biopsy collections for histopathological study. After death, the entire abdominal and pelvic cavities were fully explored and the macroscopic staging of adhesions was conducted by an independent surgeon, and the developed adhesions were graded blindly according to Kruskall-Wallis Scale (13), (see Table 1). Biopsy samples were collected from the adhesion sites (16), and were preserved in identified jars containing sufficient amounts of freshly prepared $10 \%$ buffered formalin solution for further histopathological processing. The histological sections were filmed $(5-6 \mu \mathrm{m})$, stained with hemotoxylin and eosin, and examined with light microscope by an independent pathologist (17). The fibrosis scale method shown in Table (2), was used by (18) for the microscopic assessment of the histopathological interpretations. 
Table 1: Kruskall-Wallis method's scale used on the rabbits of both groups (CG and CT) for the P.M. assessment of the P.O. intraperitoneal adhesions formation (13).

\begin{tabular}{|l|l|}
\hline Grade & Adhesion Description \\
\hline 0 & No adhesion \\
\hline 1 & Thin or narrow, easily separable adhesions \\
\hline 2 & Thick adhesions limited to one area \\
\hline 3 & Thick and widespread adhesion \\
\hline 4 & $\begin{array}{l}\text { Thick and widespread adhesion +adhesion of viscera to the anterior } \\
\text { and posterior abdominal wall }\end{array}$ \\
\hline
\end{tabular}

Table 2: Scale for microscopic assessment of fibrosis (18).

\begin{tabular}{|l|l|}
\hline Grade & Histopathological Signs \\
\hline 0 & No fibrosis \\
\hline 1 & Thin bunches of a cellular fibrosis \\
\hline 2 & Wide areas of fibrosis with reduced vascularization \\
\hline 3 & Areas of fibrosis formed by thick bunch of collagen \\
\hline
\end{tabular}

Statistical calculations were performed using Statistical Package for Social Science (SPSS) for windows, version 16.0. To compare between the numbers of adhesions on $14^{\text {th }}$ and $21^{\text {st }}$ days for both groups (CG and TG), non parametric Mann-Witney U- Test was used. When $p$ value was less than 0.05 , the score was regarded as significant. All represented data were shown as Mean $\pm \mathrm{SD}$.

\section{Results}

Generally, the rabbits on both groups did not showed evidence of anesthetic and postoperative (P.O.) complications. Only one rabbit died (from TG), 72 hours P.O. and on P.M. examination the cause for death was concluded not due adhesion formation, but to gastric dilatation and volvulus. So, the rabbit was replaced by another, on which the same experimental protocols and surgical procedures were applied. The ethical, standardized surgical and P.O. procedures, applied during the course of the experiment, was well tolerated by the animals.

Examinations of the abdominal and pelvic cavities during autopsy revealed no residual viscous solution and ascites. It was noticed that I.P. adhesions was developed in all CG rabbits. While in TG rabbits, 7 out of 10 rabbits did not showed gross I.P. adhesions.

Interestingly, on CG rabbits, the sizes of the developed adhesions on day $14^{\text {th }}$ were smaller than those seen on day $21^{\text {st }}$, and were generally of fibrotic structures in nature, moderately dense and firmly attached on involved organs. While, on TG rabbits, their sizes were mild and easily detached from the organs, i.e., clinically of least importance.

The scores for the gross P.M. findings in CG rabbits on the $14^{\text {th }}$ P.O. day, was graded between scores (1) and (2). Generally, the developed adhesions were mild to moderate in their extension, and were filmy transparent bands of white thin fibrous adhesions, extending from the abraded site on the colon to the visceral abdominal wall and/or joining the colon, in deferentially with other parts of the gut (Figure 3; Table 3). On the $21^{\text {st }}$ P.O. day, the grades for the adhesions extension were slightly more intensed, because in 4 out of the 5 grossly examined rabbits showed score (2) adhesions (Figure 4; Table 3). On the other hand, 7 out of 10 rabbits from the TG rabbits did not develop gross signs of I.P. adhesions (Figure 5; Table 3 ). And the only 3 rabbits, that developed adhesions at both P.M. phases, were at their lowest grade (score 1) (Figure 6; Table 3). The Mean \pm SD for the rate of extention of adhesions scoring for the rabbits in both CG and CT are showen in Table 4. While, statistically the results on day $14^{\text {th }}$, showed no significant differences $(\mathrm{P}<0.05)$ in the scores of adhesions between the two experimental groups (CG and TG), but the adhesion size was smaller in the 
TG $(0.40 \pm 0.548)$ compared to the CG $(1.40 \pm 0.548)$ as shown in Table (4). The same result was appeared at $21^{\text {st }}$ days with an average value for the TG $(0.20 \pm 0.447)$ which was less than the mean value for the CG $(1.80 \pm 0.447)$ as shown in Table (4). The average mean value of $\mathrm{CG}$ at $14^{\text {th }}$ P.O. days was less than the average mean value of the same group at $21^{\text {st }}$ P.O. days. While, at TC the average mean value at $21^{\text {st }}$ days was less than the average value of the same group at the $14^{\text {th }}$ P.O. days.

Table 3: The scores for the grade of extension of adhesion in each rabbit in both CG and TG as found at P.M. examinations at the $14^{\text {th }}$ and $21^{\text {st }}$ P.O. days.

\begin{tabular}{|l|l|l|l|l|l|l|l|l|l|l|l|}
\hline Groups & \multirow{3}{*}{ Scores at the 14 } & \multicolumn{3}{|c|}{ P.O. day } & \multicolumn{3}{|c|}{ Scores at the 21 ${ }^{\text {st }}$ P.O. days } \\
\cline { 3 - 13 } & & 0 & 1 & 2 & 3 & 4 & 0 & 1 & 2 & 3 & 4 \\
\hline CG & 10 & 0 & 2 & 3 & 0 & 0 & 0 & 1 & 4 & 0 & 0 \\
\hline TG & 10 & 3 & 2 & 0 & 0 & 0 & 4 & 1 & 0 & 0 & 0 \\
\hline
\end{tabular}

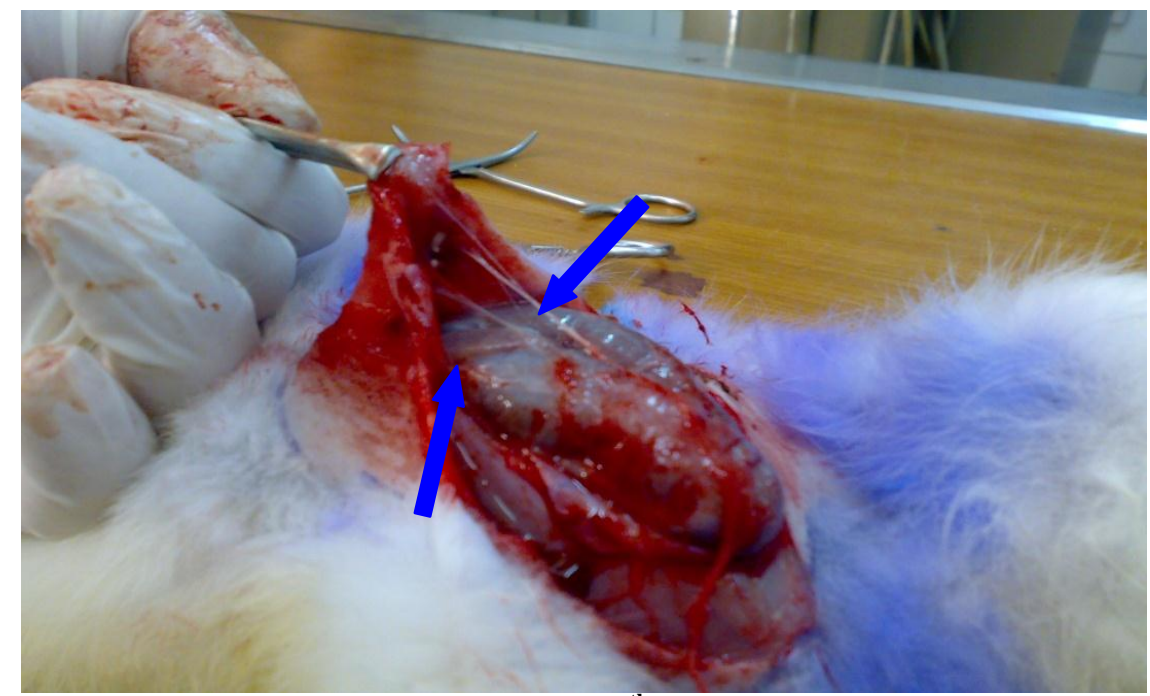

Figure 3: Gross photograph of a rabbit in CG, at the $14^{\text {th }}$ P.O. day. Fine filmy transparent bands of white thin fibrous adhesions were developed between the visceral abdominal wall and different parts of the colon (score 2). (As indicated by the two blue arrows).

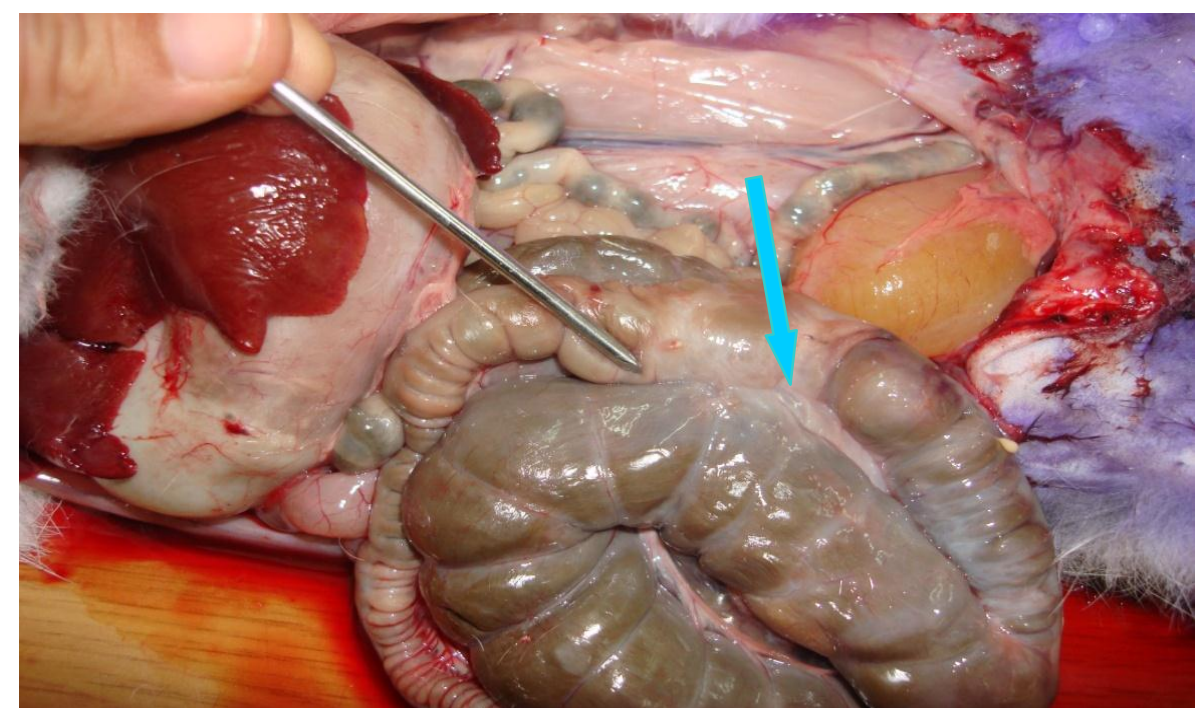

Figure 4: Gross photograph of a rabbit of CG on the $21^{\text {st }}$ P.O. day with gross appearance of large intestinal adhesions (score 2) (as indicated by blue arrow) 


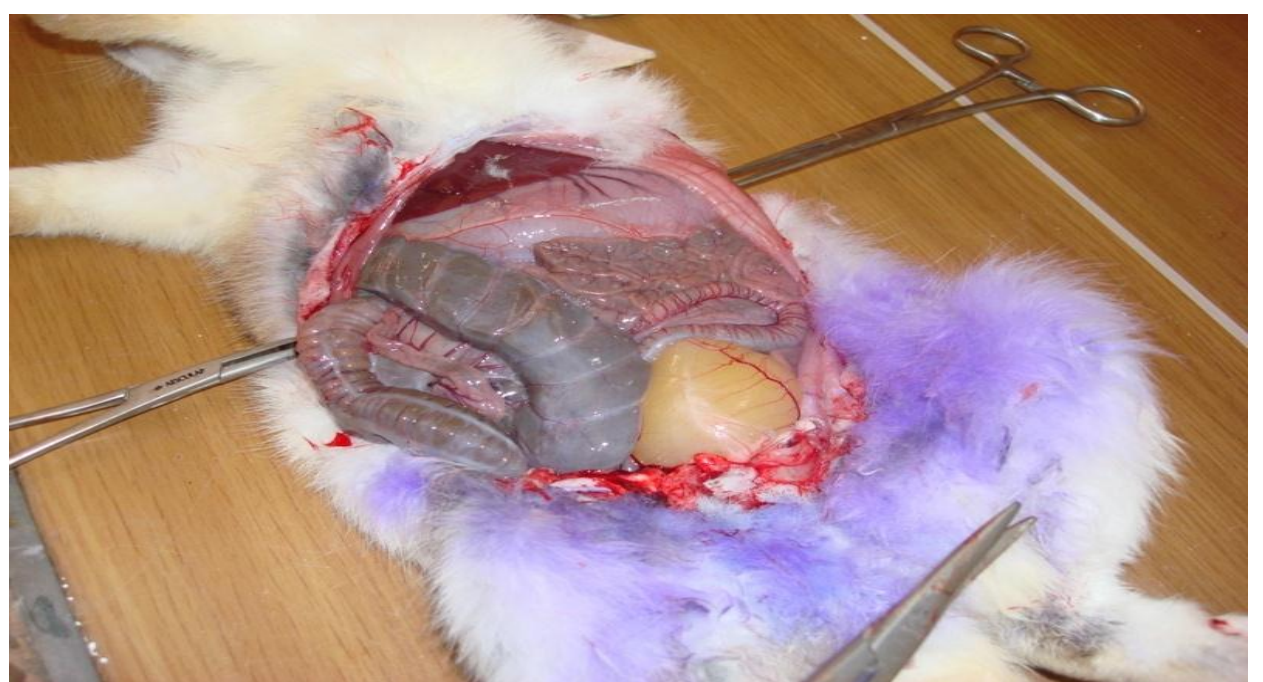

Figure 5: Gross photograph of a rabbit in TG on the $21^{\text {st }}$ P.O. day shows score (0) adhesion, because P.M.examination did not reveals gross signs of I.P. adhesion formation.

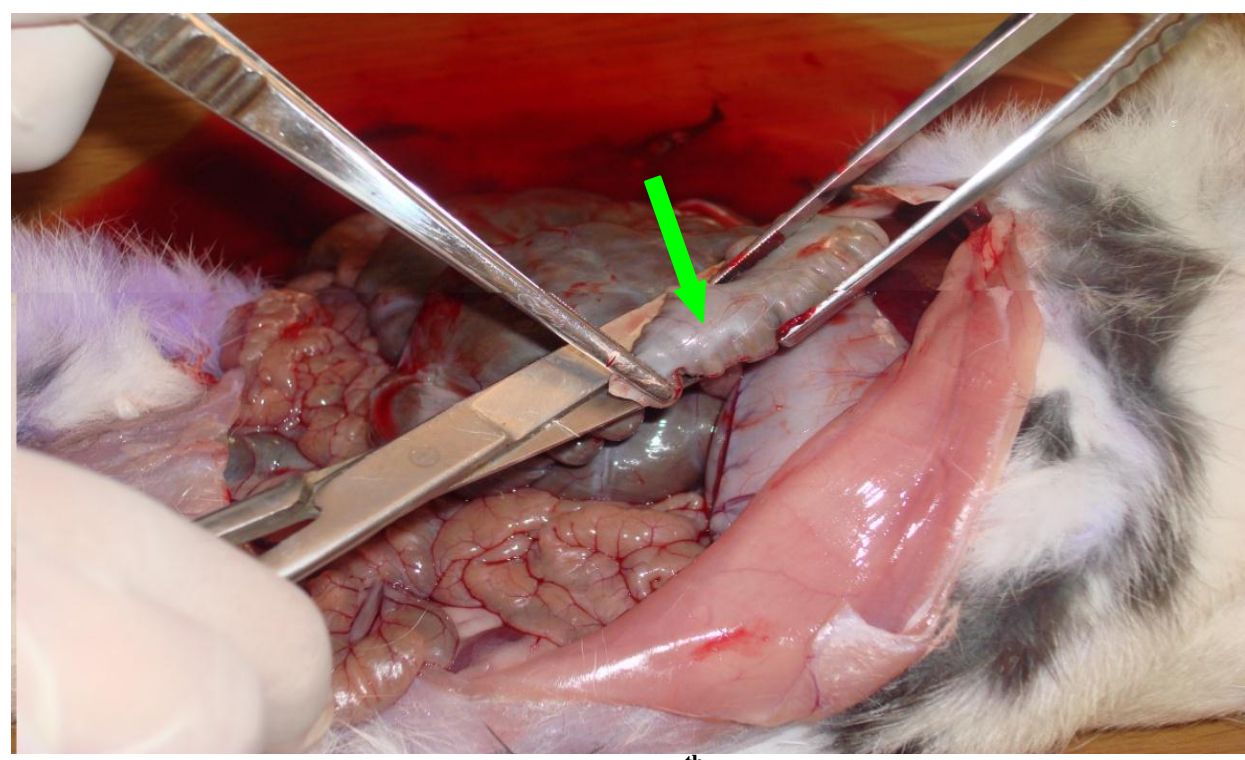

Figure 6: Gross photograph for a rabbit in TG on the $14^{\text {th }}$ P.O. day shows score (1) adhesion (as indicated by green arrow) at the area where the serosa and subserosal layers was abraded on the anti-mesenteric surface of the ascending colon.

Table 4: The Mean \pm SD for the rate of extension of adhesion scoring for the experimental rabbits in both groups CG and CT.

\begin{tabular}{|c|c|c|c|}
\hline Groups & $\begin{array}{c}\text { Numbers of } \\
\text { Rabbits }\end{array}$ & $\begin{array}{c}\text { Scores rate for } \\
\text { extension of } \\
\text { adhesions at } 14^{\text {th }} \\
\text { P.O day } \\
\end{array}$ & $\begin{array}{c}\text { Scores rate for } \\
\text { extension of } \\
\text { adhesions at } 21^{\text {st }} \\
\text { P.O day } \\
\end{array}$ \\
\hline CG & 10 & $1.40 \pm 0.548$ & $1.80 \pm 0.447$ \\
\hline TG & 10 & $0.40 \pm 0.548$ & $0.20 \pm 0.447$ \\
\hline
\end{tabular}

The histopathological findings of adhesions differed significantly among both the CG and TG with respect to fibrosis, inflammation and vascular proliferation. The CG showed the highest scores for fibrosis, heavy infiltration of inflammatory cells and loss of integrity of the serosal surface, while the TG showed slight infiltration of inflammatory cells within the serosal layers, slightly normally appearing muscular and serosal layers of the colon. In CG, moderate to severe proliferated adhesive tissues extended outward and angiogenesis were 
found as shown in figures 7 and 8. Instead, the microscopic findings in TG showed a marked decrease in the proliferation of adhesive tissues as shown in Figures 9 and 10.

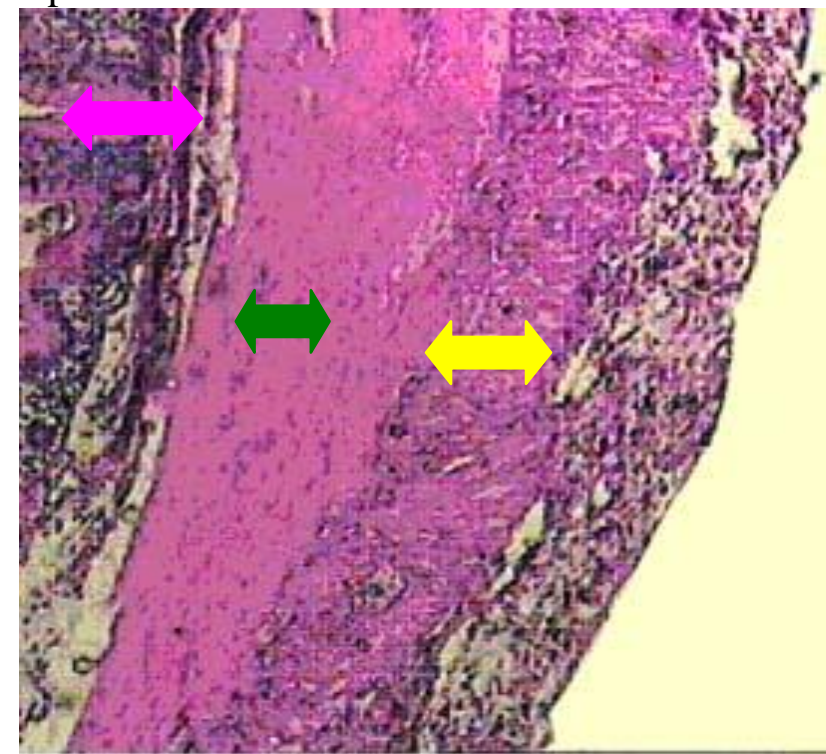

Figure 7: Histomicrographs of rabbit colon in the CG on the $14^{\text {th }}$ P.O. day. The presence of moderate to severe proliferated adhesive tissues extended outward (as indicated by yellow arrow). The green arrow shows longitudinal muscle fibres, and the pink arrow shows the circular muscle fibres. H\&E (X100).

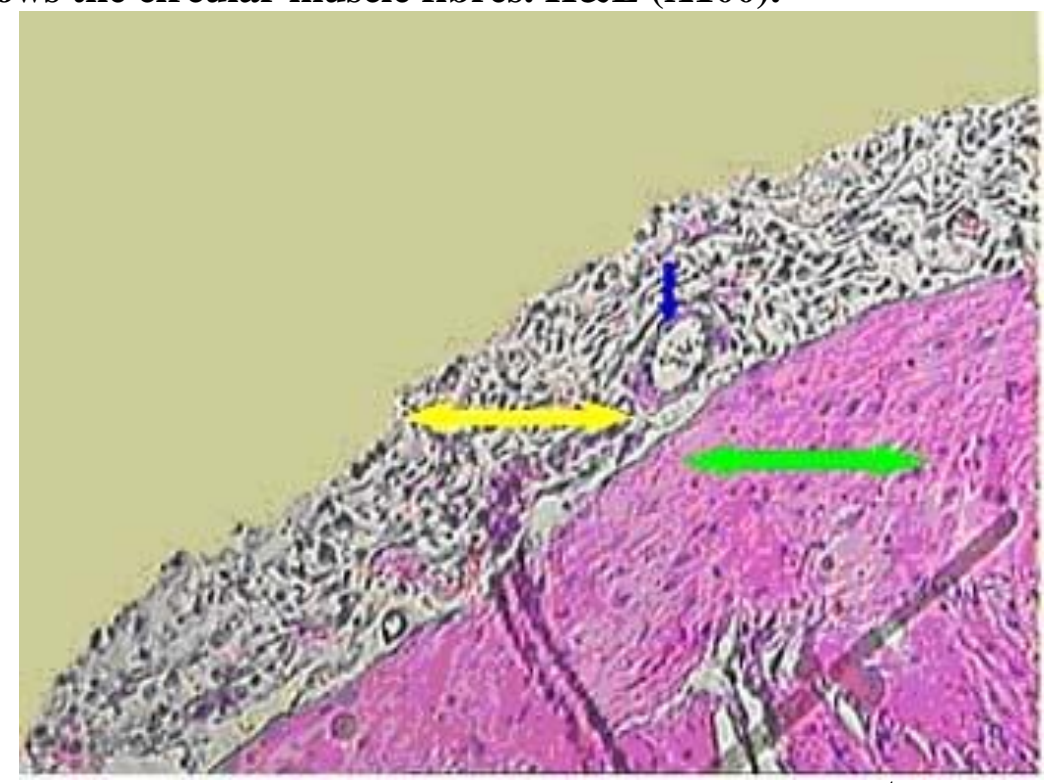

Figure 8: Histomicrographs of rabbit colon in the CG on the $21^{\text {st }}$ P.O. day. The presence of moderate proliferated adhesive tissues extended outward (as indicated by yellow arrow), new capillary formation (indicated by blue arrow). Green arrow shows longitudinal muscle. H\&E (X100). 


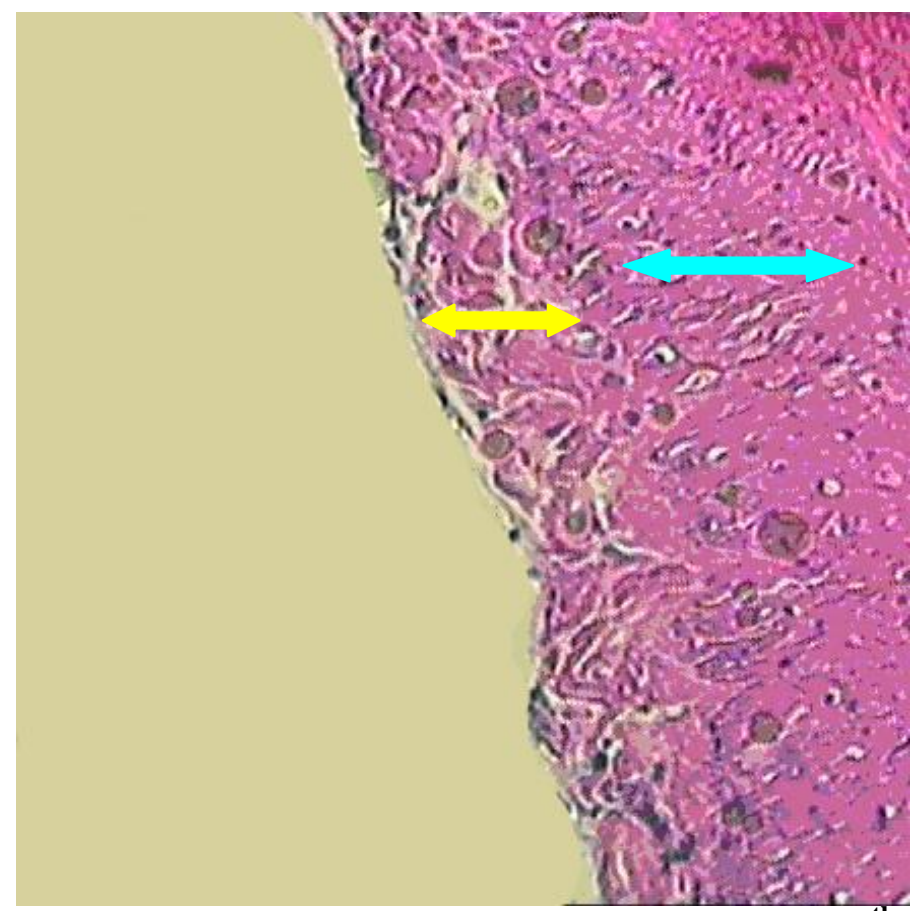

Figure 9: Histomicrographs of rabbit's colon in TG on the $14^{\text {th }}$ postoperative day. Marked lesser proliferation of adhesive tissues (as indicated by white arrow); Yellow arrow shows Circular muscle fibre; Blue arrow shows longitudinal muscle fibre. H\&E (X100).

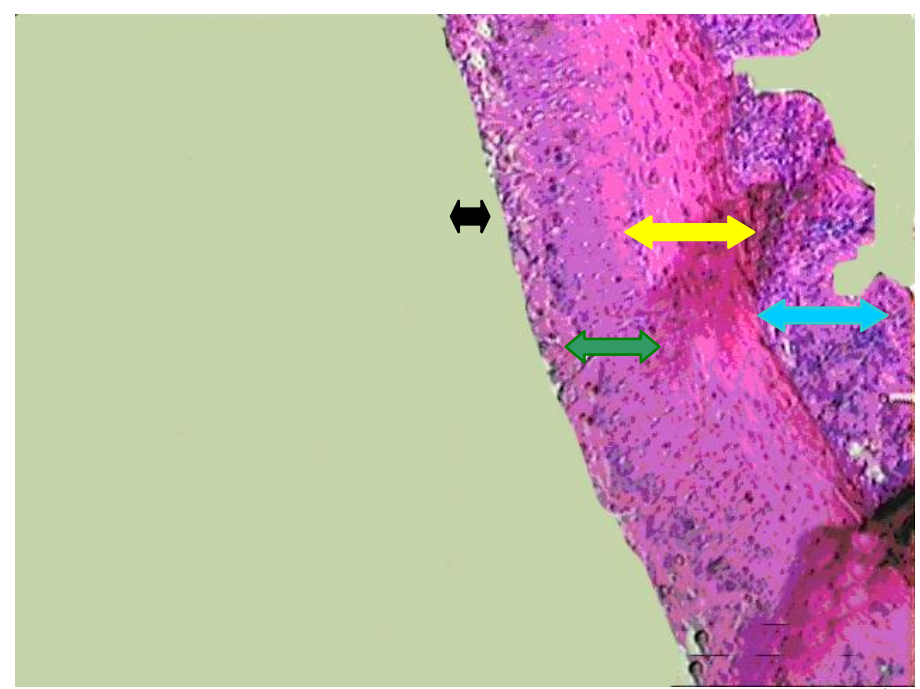

Figure 10: Histomicrographs of rabbit's colon in TG on the $21^{\text {st }}$ P.O. An eextensive decrease in the proliferation of adhesed colon layers, as indicated by black arrow; the yellow arrow shows the circular muscle fibres, the green arrow shows longitudinal muscle fibres, and blue arrow shows the lamina properia. H\&E (X100).

\section{Discussion}

In this study, all CG rabbits had adhesions, indicating the predictability of the adhesion model. Choosing rabbits, for the induction of adhesion, coincides in the present study with the essentialness and importance of an animal model. Because the experimentally induced adhesions by the mechanically abraded method to the serosal and subserosal layers of the ascending colons of the rabbits successfully developed the formation of adhesion accordingly, this research is conducted to study their mechanisms of formations and the strategies for their prevention (19). This adhesion model was chosen because serosal trauma has been established as reliable means of adhesion formation in rabbits. Formation of adhesions begins during the inflammatory stage of healing, 24 to 48 hours after the injury, and the adhesions 


\section{Proceeding of the Eleventh Veterinary Scientific Conference, 2012; 214-224}

usually are well formed by the $5^{\text {th }}$ to the $7^{\text {th }}$ days after the injury (20). In this study, the results of adhesion formation was not evaluated only by the presence or absence of fibrous adhesions, but also by the degree of their formation. The majority of methods for grading adhesions are based on the character of the adhesions; strong or weak and fibrinous or fibrous. Other methods include; evaluation of the percentage of the traumatized area covered by adhesion; measurement of surface area involved; enumeration of adhesions present; or simply the presence or absence of adhesions (21).

Postoperative adhesion formation in the peritoneal and pelvic cavities is a fibrotic tissue disorder manifested by excessive deposition of fibrin during normal wound healing. It is currently believed that a breakdown in the balance between fibrin deposition (fibrinogenesis) and fibrin degradation (fibrinolysis) during wound healing leads to this surgical complications (22). In order to reduce adhesion formation and reformation, an agent must separate damaged surfaces during the fundamental phases of post surgical repair (23). Several drugs and substances were used locally or systematically for that purpose. So far, there is no safe and effective prophylaxis available for intra abdominal adhesions. Scientists try to find the answer from studying the exact mechanism of intra-abdominal adhesions, thus various experiments have been conducted to elaborate the exact mechanism of intra-abdominal adhesions and its prevention (24). The $2 \mathrm{ml} 1 \%$ methylene blue solution, used in this investigation produced $70 \%$ reduction in the percentage of adhesion formation in comparison to the $100 \%$ adhesions development in the CG rabbits that did not received intraperitoneal methylene blue treatment. This result, undoubtedly prove the essentially of this easily acceptable, cheap and simply prepared antiadhesive agent. This result highly coincides with findings by previous researcher on the antiadhesion activity of intra-abdominally applied methylene blue in rats, at which they found that methylene blue $1 \%$, and to lesser degree $0.5 \%$, had the best anti-adhesion potential, (25). Methylene blue acts as an antioxidant and reduces intra-abdominal adhesion formation by enhancing peritoneal fibrinolytic activity following surgery (26). In addition methylene blue is thought to be very effective in preventing formation of peritoneal adhesions, and its activity is probably through inhibition of free-radical generation and not of nitric oxide action (14). The effective action of $1 \%$ solution of methylene blue applies intraperitonially following laparotomy in adhesion prevention and/or reduction in this study was confirmed microscopically, as the results showed that the highest fibrosis scores were in the biopsy samples obtained from the CG specimens, while the lowest inflammation and vascular proliferation scores were from the methylene blue treated animals. Such results was also confirmed by (27). While, in this study the impact negative or positive effects of the intraabdominally applied sterile $0.09 \%$ of saline solution in the CG rabbits, on adhesion formation was not studied. Where, some workers published that its administrations might reduce peritoneal adhesion formation, probably by altering peritoneal fibrinolytic activity (28). However, this needs further more investigation.

In conclusion, standardized surgical techniques is fundamental to any adhesion reduction, and the intraperitonially applied $1 \%$ sterile methylene blue solution following conventional laparotomy was an excellent, cost benefit, easily accessed and applied, and none side effect antiadhesive agent. However, further researches are needed to be establishing its safety and effectiveness in farm animal subjects.

\section{References}

1. Tsai, S-W.; Fang, J-F.; Yang, C.L.; and Chen, J.H. (2005). Preparation and evaluation of hyaluronate collagen film for preventing post-surgical Adhesion. The Journal of International Medical Research, 33: 68-76.

2. Nappi, C.; Sardo, D.; Greco, E.; and Bifulco, G. (2007). Prevention of adhesions in gynecological endoscopy. Human Reproduction up date, 13(4): 379-394.

3. Yeo, Y.; and Daniel, S.K. (2008). Polymers in the prevention of peritoneal adhesion. Eur J Pharm Biopharm, 68(1):57-66. 


\section{Proceeding of the Eleventh Veterinary Scientific Conference, 2012; 214-224}

4. Demirturk, F.; Aytan, H.; Caliskan, A.; Aytan, P.; Yener, T.; Koseoglu, D.; and Yenisehirli (2006). The effect of rosiglitazonein the prevention of intra-abdominal adhesion formation in rat uterine horn model. Human Reproduction, 21(11): 30083013.

5. Burns, J.W.; Cox, S.; and Walt's, A.E. (1991). Water Insoluble Derivatives of Hyaluronic Acid: United States Patent Number 5, 017, 229.

6. Chegini, N.; Kotseos, K.; Zhao, Y.; and Holmdahl, 1. (2001). Differential expression of TGF_B1 and TGF_B3 in serosal tissue of human intraperitoneal organs and peritoneal adhesion. Human Reproduction, 16 (6): 1291-1300.

7. Sousa, A.A.; Petroioanu, A.; Neto, T. and Barbosa, A.J.A. (2001). Effect of Sodium Carboxy Methyle Cellulose and Methyl Prednisolone on the healing of jejunal anastomosis in rats. Brazilian Journal of Medical and Biological Research, 34: 519-523.

8. Butz, N.; Muller, A.; Treutner, H.K.; Anurov, M.; Oettinger, P.A.; Schumpelick, V. (2007): The influence of blood on the efficacy of intraperitoneally applied phospholipids for prevention of adhesions. BMC Surgery, 7: 14.

9. Wiseman, D. (1998). A patients guide to adhesions and related pain or you are not alone. www.obgyn.net.

10. Krabben, V.D.; Dijkstra, F.R.; Nieuwenhuijzen, M.; and Reijen, M.M.P.J. (2000): Morbidity and mortality of inadvertent enterotomy during adhesiostomy. Br J Surg, 87: 467-471.

11. Trew, G. (2006). Adhesion Reduction Option. Future direction in surgery. www.touchbriefing.com.

12. Maghsoudi, H.; and Behnam, A. (2008). The effect of piroxicam on the formation of post operative, intra-abdominal adhesion. The Saudi Journal of Gastroenterology, 14(4): 198201.

13. Ali, C.; Ali, E.U.; Emre, E.; Ahmet, K.; and Murat, E.B. (2008). Which is most effective in prevention of postoperative intraperitoneal adhesions-methylene blue, low molecular weight heparin or vitamin E: an experimental study in rats. The Internet Journal of Surgery, 15 (1): 1-12.

14. Yair, G.; Abraham, B.; Weinbroum, R.; Marmur, A.; Iaina, S.; Volman, A.; Peer, Y.; Szold, G.; Soffer, O.D.; Klausner, D.; Josef, K.M. (1998). Methylene Blue Prevents Pulmonary Injury after Intestinal Ischemia-Reperfusion. The Journal of Trauma: Injury, Infection, and Critical Care, 45 (2): 222-226.

15. William, W.M. and John, A.E. (1995). Handbook of Veterinary Anaesthesia $2^{\text {nd }}$ Ed., pp: 366-367.

16. Alizzi, A. (2005). Reduction of post-surgical peritoneal adhesions using a pig model. M.Sc. Thesis, James Cook University.

17. Toosie, K.; Gallego , K.; Stabiley , B.; Schaber, B.; French, S.; and Virgilo, C. (2000). Fibrin glue reduce intra-abdominal adhesions to synthetic mesh in a rat ventral hernia model. American Surgery, 66: 41-45.

18. Yilmaz, H.G.; Tacyildiz, I.H.; Keles, C.; Gedik, E.; Kilinc, N. (2005). Micronized purified flavonoid fraction may prevent formation of intraperitoneal adhesions in rats. Fertility Sterility, 84 (suppl 2): 1083-1088

19. Murat, B.O.; Lufang, Z.; Hakan, C.; and Aydin, U. (2005). Inhibition of chemokines prevents intraperitoneal adhesions in mice. Human Reproduction, 20 (11): 3047-3052.

20. Moll, D.H.; Schumacher, J.; Wright, C.J.; and Spano, S.J. (1991). Evaluation of sodium carboxymethyle cellulose for prevention of experimentally induced abdominal adhesion in ponies. American Journal Veterinary Research, 52: 738-741.

21. Singer, E.R.; Livesey, MA; Barker, I.K.; Hurtig, M.B.; and Conlon, P.D. (1996). Utilization of the serosal scarification model of postoperative intestinal adhesion formation to investigate potential adhesion preventing substances in the rabbits. Canadian Journal Veterinary Research, 60: 305-311. 
22. Chung, D.R.; Chitinis, T.; Panzo, J.R.; Kasper, L.D.; Sayegh, H.M. and Tzianabos O.A. (2002). CD4 $+\mathrm{T}$ cells Regulate surgical and post infectious adhesion formation. Journal Experimental Medicine, 195 (11): 1471-1478.

23. Verco, J.S.; Peers, M.E.; Brown, B.C.; Rodgers, E.K.; Roda, N.; and diZerega, G. (2000). Development of a novel glucose polymer solution (icodextrin) for adhesion prevention. Preclinical studies. Human Reproduction, 15(8):1764-1772.

24. Li-Wang,Y.; En Pan,C.; Lin Yang, P.; Tian,Y.; Wen Pei, S.; and Dong, M. (2004). Effect of Antiadhesion preparation on free fibrinogen and fibrin degrading products in abdominal exudates of rabbits postoperatively. World Journal Gastroenterology,10(18): 2762-2766.

25. Kluger, Y.; Avraham, R.; Galli, Y.; Klausner, J.; and Rabau, M. (2003). Reduction in formation of peritoneal adhesions by methylene blue in rats. European Journal Surgery, 166 (7): 568-571.

26. Heydrick, S.; Reed, K.; Cohen, P.; Aarons, C.; Gower, A.; Becker, J.; and Stucchi, A. (2009). Intraperitoneal administration of methylene blue attenuates oxidative stress, increases peritoneal fibrinolysis, and inhibits intraabdominal adhesion formation. Journal Surgical Research, 143: 311-319.

27. Irkorucu, O.; Ferahköşe, Z.; Memiş, L.; Ekinci, O.; Akın, M. (2009). Reduction of postsurgical adhesions in a rat model: a comparative study. Clinics, São Paulo; 64(2): 245252.

28. Tarhan, O.R. ; Barut, I. ; Sezik, M. (2008). An Evaluation of Normal Saline and Taurolidine on Intra-Abdominal Adhesion Formation and Peritoneal Fibrinolysis. Department of General Surgery, Faculty of Medicine, Suleyman Demirel University, Isparta, Turkey. 